\title{
Lacrimal gland abscess presenting with preseptal cellulitis depicted on CT
}

Daniel Thomas Ginat ${ }^{1 *}$, Lora Rabin Dagi Glass² ${ }^{2}$ Fatoumata Yanoga ${ }^{3}$, Nahyoung Grace Lee ${ }^{2}$ and Suzanne K. Freitag ${ }^{2}$

\begin{abstract}
Background: Pyogenic lacrimal gland abscesses are uncommon and thus may not be immediately clinically recognized without a high index of suspicion.

Findings: We present two patients with preseptal cellulitis and characteristic low-attenuation fluid collections in the lacrimal glands demonstrated on computed tomography (CT).

Conclusions: Lacrimal gland abscesses should be considered when dacryoadenitis is refractory to medical treatment. Indeed, these cases highlight the value of prompt recognition of lacrimal abscess through ophthalmologic referral and the use of diagnostic imaging. Both patients were successfully treated via incision and drainage.
\end{abstract}

Keywords: Lacrimal gland abscess, Bacterial, Cellulitis, CT

\section{Findings}

\section{Introduction}

Lacrimal gland bacterial abscesses are uncommon and may arise in the setting of acute dacryoadenitis, which may in turn develop secondary to an adjacent infection, such as rhinosinusitis, from hematogenous spread of bacteremia or after trauma $[1,2]$. We present two patients with lacrimal gland abscess presenting with preseptal cellulitis depicted on computed tomography (CT).

\section{Case reports}

Patient 1 . The patient is a 2-year-old male who presented with 8 days of right eyelid swelling. Initially, the patient's primary care physician diagnosed preseptal cellulitis and gave a 5-day course of oral clindamycin $15 \mathrm{~g} /$ $\mathrm{ml}$ BID. The eyelid swelling initially decreased after initiation of the antibiotics, but after 3 days, the right eyelid swelling increased to the point that the patient had nearly complete ptosis. The patient was then referred to ophthalmology whereby an examination revealed right preseptal erythema and swelling, conjunctival injection and chemosis, and decreased abduction. There was no afferent pupillary defect in the affected eye. A contrastenhanced CT of the orbits was obtained, which showed

\footnotetext{
* Correspondence: dtg1@uchicago.edu

${ }^{1}$ Department of Radiology, University of Chicago, Pritzker School of Medicine, 5841 S Maryland Avenue, Chicago, IL 60637, USA

Full list of author information is available at the end of the article
}

right preseptal swelling, as well as marked enlargement of the right lacrimal gland with an area of central low attenuation, and swelling of the adjacent extra-ocular muscles (Fig. 1). An orbitotomy with drainage was performed with culture of purulent abscess contents. The cultures grew methicillin-resistant Staphylococcus aureus susceptible to sulfamethoxazole/ trimethoprim. After completing a 3-week course of sulfamethoxazole $(40 \mathrm{mg}) /$ trimethoprim $(8 \mathrm{mg})$ BID $\mathrm{PO}$ and tobramycin ointment, the patient's symptoms had resolved.

Patient 2. The patient is a 60 -year-old female with a past medical history of asthma and hypertension who presented with right upper lid swelling and pain for 4 days, purulent discharge, and limited supraduction and abduction of the right eye. A contrast-enhanced CT demonstrated right preseptal cellulitis, lacrimal gland swelling, and fluid collection (Fig. 2). An initial eye swab culture yielded abundant diphtheroids and S. aureus susceptible to sulfamethoxazole/trimethoprim. Incision and drainage of the abscess was subsequently performed, and the patient was discharged on polymyxin B sulfate and trimethoprim ophthalmic solution and PO sulfamethoxazole $(800 \mathrm{mg}) /$ trimethoprim $(160 \mathrm{mg})$ BID for 3 weeks, which led to resolution of the infection.
望 Springer

(C) 2016 Ginat et al. Open Access This article is distributed under the terms of the Creative Commons Attribution 4.0 International License (http://creativecommons.org/licenses/by/4.0/), which permits unrestricted use, distribution, and reproduction in any medium, provided you give appropriate credit to the original author(s) and the source, provide a link to the Creative Commons license, and indicate if changes were made. 


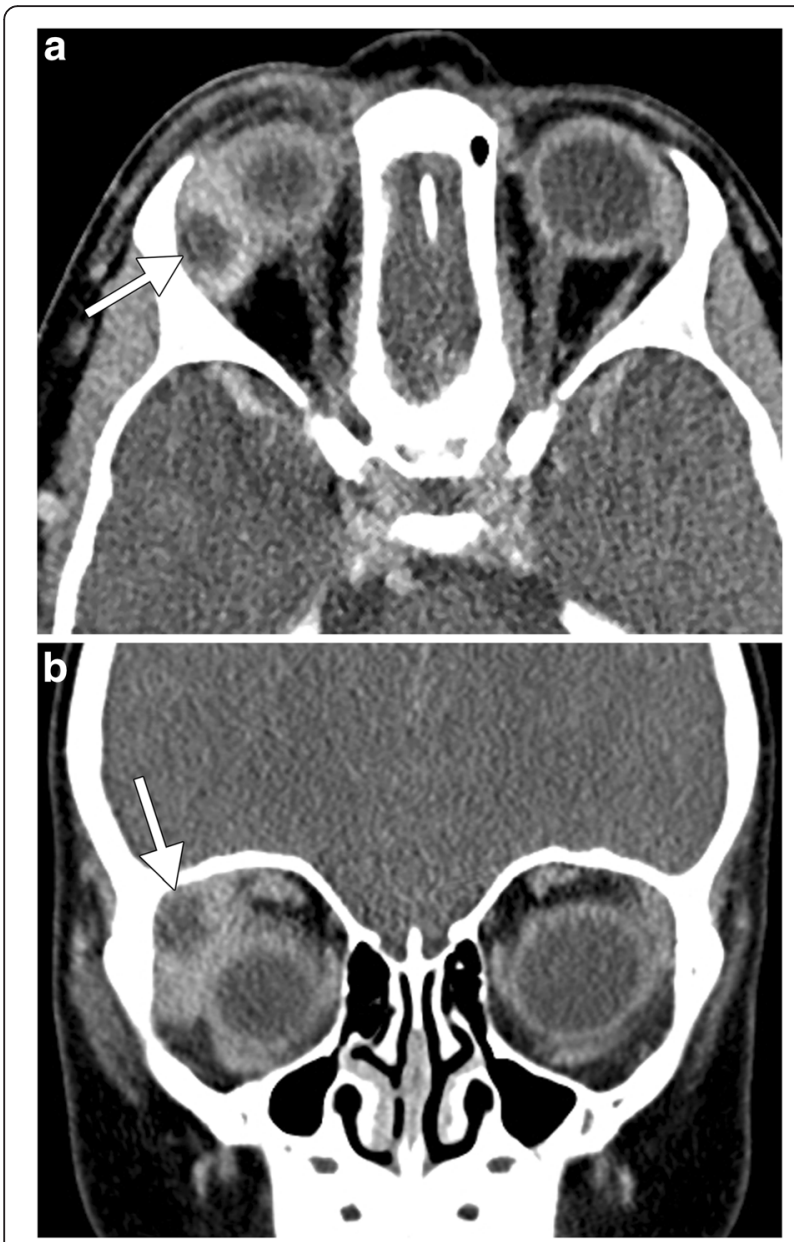

Fig. 1 Axial (a) and coronal (b) contrast-enhanced CT images demonstrate right preseptal swelling and fat stranding as well as swelling and hyperenhancement of the right lacrimal gland, which contains a fluid collection (arrow)

\section{Discussion}

Although pyogenic lacrimal gland abscesses are rare, these lesions are of clinical significance since, as in this case, the abscess may not improve with medical therapy alone and may require surgical drainage. Furthermore, if inadequately treated, patients may progress to more widespread and sometimes life-threatening involvement including intracranial abscesses, meningitis, and cavernous sinus thrombosis [3].

Radiological imaging plays an important role in the evaluation of complicated orbital infections [3, 4]. Both $\mathrm{CT}$ and magnetic resonance imaging (MRI) of the orbits and brain with contrast are valid imaging modalities for the evaluation of intraorbital abscesses and associated intracranial abnormalities. Technique with low ionizing radiation dose can be implemented, particularly for pediatric patients, without significantly compromising diagnostic performance, as in case of patient 1. Imaging may also be useful for detecting potential predisposing
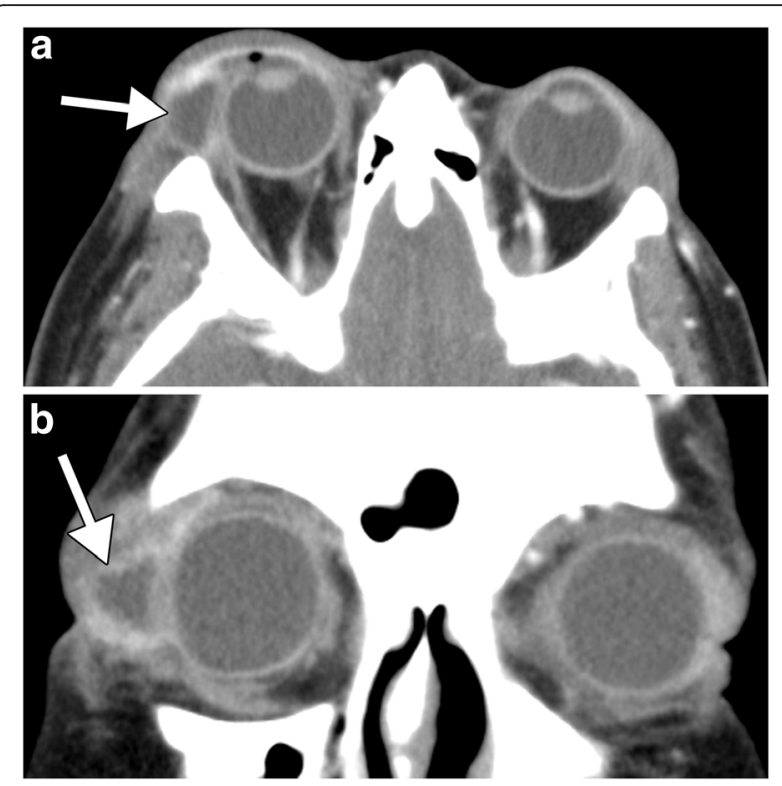

Fig. 2 Axial (a) and coronal (b) contrast-enhanced CT images demonstrate right preseptal swelling and fat stranding and a fluid collection within the lacrimal gland (arrow)

factors, such as rhinosinusitis and lacrimal gland ductal cyst $[1,2]$.

Lacrimal gland abscesses appear as characteristic lowattenuation areas within an enlarged lacrimal gland on CT [5]. There can also be diffuse enlargement and hyperenhancement of the affected lacrimal gland parenchyma surrounding the abscess. There is frequently associated orbital cellulitis. MRI with diffusion-weighted imaging can demonstrate restricted diffusion within the abscess. Nevertheless, the differential diagnosis for lacrimal abscess on imaging may include lacrimal gland tumors, lymphoproliferative disorders, foreign body granulomas, and sarcoidosis.

In conclusion, it is essential to recognize the presence of lacrimal gland abscesses, since these require incision and drainage. Therefore, diagnostic imaging of the orbits should be performed to evaluate for an underlying abscess in cases of medically refractory or atypical dacryoadenitis.

\section{Abbreviations}

CT: computed tomography; MRI: magnetic resonance imaging.

\section{Competing interests}

The authors declare that they have no competing interests.

\section{Authors' contributions}

All authors participated in collecting the data and drafting the manuscript, read, and approved the final manuscript.

Acknowledgements

None. 


\section{Author details}

'Department of Radiology, University of Chicago, Pritzker School of Medicine, 5841 S Maryland Avenue, Chicago, IL 60637, USA. ²Department of Ophthalmology, Massachusetts Eye and Ear Infirmary, Harvard Medical School, Boston, MA, USA. ${ }^{3}$ Department of Ophthalmology, University of Chicago, Pritzker School of Medicine, Chicago, USA.

Received: 15 April 2015 Accepted: 7 December 2015

Published online: 12 January 2016

\section{References}

1. Patel N, Khalil HM, Amirfeyz R, Kaddour HS (2003) Lacrimal gland abscess complicating acute sinusitis. Int J Pediatr Otorhinolaryngol 67(8):917-919

2. Mirza S, Lobo CJ, Counter P, Farrington WT (2001) Lacrimal gland abscess: an unusual complication of rhinosinusitis. ORL J Otorhinolaryngol Relat Spec 63(6):379-381

3. Eustis HS, Mafee MF, Walton C, Mondonca J (1998) MR imaging and CT of orbital infections and complications in acute rhinosinusitis. Radiol Clin North Am 36(6):1165-1183, xi

4. Parvizi N, Choudhury N, Singh A (2012) Complicated periorbital cellulitis: case report and literature review. J Laryngol Otol 126(1):94-96

5. McNab AA (1999) Lacrimal gland abscess: two case reports. Aust N Z J Ophthalmol 27(1):75-78

\section{Submit your manuscript to a SpringerOpen ${ }^{\odot}$ journal and benefit from:}

- Convenient online submission

- Rigorous peer review

- Immediate publication on acceptance

- Open access: articles freely available online

High visibility within the field

- Retaining the copyright to your article

Submit your next manuscript at $\gg$ springeropen.com 